\title{
Extended magnetic resonance imaging studies on the effect of classically activated microglia transplantation on white matter regeneration following spinal cord focal injury in adult rats
}

\author{
WIESŁAW MARCOL ${ }^{1}$, WOJCIECH ŚLUSARCZYK ${ }^{1}$, MAGDALENA LARYSZ-BRYSZ ${ }^{1}$, \\ KRZYSZTOF ŁABUZEK ${ }^{2}$, BARTOSZ KAPUSTKA ${ }^{1}$, RAFAŁ STASZKIEWICZ ${ }^{1}$, PAULINA ROSICKA ${ }^{3}$, \\ KATARZYNA KALITA $^{3}$, WŁADYSŁAW WĘGLARZ ${ }^{3}$ and JOANNA LEWIN-KOWALIK ${ }^{1}$ \\ Departments of ${ }^{1}$ Physiology and ${ }^{2}$ Internal Medicine and Clinical Pharmacology, \\ School of Medicine in Katowice, Medical University of Silesia, 40-752 Katowice; ${ }^{3}$ Department of \\ Magnetic Resonance Imaging, Institute of Nuclear Physics Polish Academy of Sciences, 31-342 Kraków, Poland
}

Received July 29, 2016; Accepted April 28, 2017

DOI: $10.3892 / \mathrm{etm} .2017 .5130$

\begin{abstract}
Spinal cord injuries are still a serious problem for regenerative medicine. Previous research has demonstrated that activated microglia accumulate in spinal lesions, influencing the injured tissues in various ways. Therefore, transplantation of activated microglia may have a beneficial role in the regeneration of the nervous system. The present study examined the influence of transplanted activated microglial cells in adult rats with injured spinal cords. Rats were randomly divided into an experimental (M) and control (C) group, and were subjected to non-laminectomy focal injury of spinal cord white matter by means of a high-pressured air stream. In group $\mathrm{M}$, activated cultured microglial cells were injected twice into the site of injury. Functional outcome and morphological features of regeneration were analyzed during a 12-week follow-up. The lesions were characterized by means of magnetic resonance imaging (MRI). Neurons in the brain stem and motor cortex were labeled with FluoroGold (FG). A total of 12 weeks after surgery, spinal cords and brains were collected and subjected to histopathological and immunohistochemical examinations. Lesion sizes in the spinal cord were measured and the number of FG-positive neurons was counted. Rats in group $\mathbf{M}$ demonstrated significant improvement of locomotor performance when compared with group $\mathrm{C}(\mathrm{P}<0.05)$. MRI analysis demonstrated moderate improvement in water diffusion along the spinal cord in the group $\mathrm{M}$ following microglia treatment, as compared with group $\mathrm{C}$. The water diffusion perpendicular to the spinal cord
\end{abstract}

Correspondence to: Professor Wiesław Marcol, Department of Physiology, School of Medicine in Katowice, Medical University of Silesia, Street Medyków 4, 40-752 Katowice, Poland

E-mail:wmarcol@tlen.pl

Key words: spinal cord injuries, spinal cord regeneration, microglia, transplantation, magnetic resonance imaging, diffusion in group $\mathrm{M}$ was closer to the reference values for a healthy spinal cord than it was in group $\mathrm{C}$. The sizes of lesions were also significantly smaller in group $\mathrm{M}$ than in the group $\mathrm{C}$ $(\mathrm{P}<0.05)$. The number of brain stem and motor cortex FG-positive neurons in group $M$ was significantly higher than in group $\mathrm{C}$. The present study demonstrated that delivery of activated microglia directly into the injured spinal cord gives some positive effects for the regeneration of the white matter.

\section{Introduction}

Novel ways of treating the spinal cord injury (SCI) have been intensively studied. Among them, the transplantation of some cell types into the injured area is considered to be a promising approach (1). The optimal cellular candidate for the treatment of SCI should be easy to collect in a non-invasive way, and be both isolated and cultured without difficulty to reach the number appropriate for transplantation. Microglial cells appear to be a very attractive candidate due the possibility of obtaining them during low-invasive surgical procedures, such as biopsy of the brain, or the possibility to culture them from bone marrow stem cells $(1,2)$.

The effect of inflammation and immune responses in the course of damage occurring in the central nervous system (CNS) gives rise to many controversies. On one hand, it has been demonstrated that inhibition of the excessive inflammatory reaction may reduce the extent of damage; on the other hand, there is the concept of immune neuroprotection, introduced for the first time by Schwartz et al $(1,2)$. The most important cells involved in immune neuroprotection are activated microglial cells and autoreactive cells specific for myelin proteins, including T-lymphocytes infiltrating the site of injury $(3,4)$. These cells possess the ability to remove dead cells as well as limit the size of injury developing during neurodegeneration, thus stimulating neuronal regeneration (4,5). Activated microglia produce substances that may stimulate repair processes in the damaged spinal cord by increasing the survival of nerve cells and sealing of the blood-brain barrier (5). It has been demonstrated that bone marrow-derived mesenchymal 
stromal cells (MSCs), used in MSC therapy after traumatic brain injury, act as remote 'bioreactors' via stimulation of lung macrophages and augmentation of $\mathrm{T}$ regulatory cell production by the spleen, leading to systemic increases in circulating anti-inflammatory cytokines and alteration of the locoregional milieu of the CNS (6). The altered intracerebral microenvironment leads to modulation of the resident microglia population, stimulating an increase in the ratio of M2 (anti-inflammatory) to M1 (pro-inflammatory) macrophages. This effect accounts for the observed neuroprotection (6).

Microglial cells were discovered by Pio del Rio-Hortega (5). There are various controversies surrounding these cells. It is believed that they originate from monocyte lines and flow to the brain along with the development of the vascular system when the blood-brain barrier is still incomplete and underdeveloped. After reaching the brain parenchyma, they undergo in situ transformation from an amebic form into resting microglia $(7,8)$. There is an alternative theory, ascribing the origin of microglia to a common progenitor cell for astrocytes and oligodendrocytes present in the brain (9). Microglial cells in the embryonic zebrafish brain migrate to an injury site in response to an SOS signal from damaged neurons. Glutamate is most likely the strongest inducer of $\mathrm{Ca}^{2+}$-transmitted microglial attraction to the injury zone (10). Microglial cells are usually uniformly distributed throughout the whole brain and spinal cord and occur in an inactive form, representing $\sim 20 \%$ of non-neuronal cells in the brain $(7,9)$. Following a noxious stimulus that may be of mechanical, chemical or other types, microglial cells are activated, after which they proliferate and migrate to the site of injury (4). Activated in a classical $\beta$-amyloid method, microglial cells not only secrete large numbers of pro-inflammatory and neurotoxic factors, but also produce some substances of known anti-inflammatory and even neuroprotective functions, including interleukin (IL)-10, IL-11 and fibroblast growth factor (11). The pro-inflammatory factors produced by activated microglia may be enumerated as: IL-1, tumor necrosis factor (TNF) $\alpha$, IL-6, IL-12, IL-15, IL-18, chemokines (IL-8 and interferon $\gamma$-induced protein-10) and cytotoxic compounds (inducible nitric oxide synthase, free radicals of oxygen and nitrogen) and prostanoids (12).

Currently, it appears that the CNS of adult mammals is able to initiate signals that alter the function of microglia, and vice-versa, and these cells in turn release factors that regulate neuronal function, including neurogenesis (10). Previous research has demonstrated that activated microglia or blood-born macrophages accumulate in the lesions of injured spinal cords, and they may influence survival of neurons in various ways (2). It is understood that a tightly and timely regulated immune response is required for recovery. Furthermore, it is now apparent that the phenotype of microglia is not uniform, and that in response to different stimuli these cells may acquire either destructive or rather beneficial phenotypes (2). Therefore, transplantation of properly activated, stage-dependent microglial cells may have a crucial role in the process of regeneration of the nervous system. These ideas could be achieved in different ways. For example, a study by Yaguchi et al (13) indicated that IL-12 administration (secreted by dendritic cells) or direct dendritic cells transplantation into injured adult spinal cords resulted in functional recovery through the activation of the microglia/macrophage system in mice. In the present experiment, the influence of in vitro activated microglial cells on the injured spinal cords of adult rats was assessed.

\section{Materials and methods}

Animals. All procedures used in the present experiment were performed in accordance with the EU Animal Protection Law and were approved by the Local Ethics Committee for Experiments on Animals in Katowice (Katowice, Poland). A total number of 36 adult rats and 45 pups obtained from Experimental Medicine Center of Medical University of Silesia, (Katowice, Poland) were used in the present experiment. Animals were housed in individual cages with a $12-\mathrm{h}$ light/dark cycle, at $22^{\circ} \mathrm{C}$ and $40 \%$ humidity, with access to food and water ad libitum. Of the adult rats, 30 male Wistar $\mathrm{C}$ rats (weight, $\sim 0.3 \mathrm{~kg}$, age 12-14 weeks) were randomly divided into two equal $(\mathrm{n}=15)$ groups: Control (C) and experimental (M). For magnetic resonance imaging (MRI) examination, an additional group $(n=6)$ of healthy male rats (without any procedures) was used as a reference ( $\mathrm{R}$ ) group for the $\mathrm{C}$ and $\mathrm{M}$ groups. In addition, 45 2-day old male Wistar $\mathrm{C}$ rat pups (b.w. 7-9 g) were used to prepare glial cultures.

SCI procedure. The focal SCI was performed using a device that we designed and created, the pressure impactor, which produces a precisely controlled air blast, as described previously (14). Briefly, following intraperitoneal anesthesia with ketamine $(100 \mathrm{mg} / \mathrm{kg})$ and xylazine $(10 \mathrm{mg} / \mathrm{kg}$; both POLFA Łódź, Warszawa, Poland), animals were immobilized, Th9-Th11 segments of spinal cord were exposed and, under control of a stereomicroscope (Nikon SMZ 800; Nikon Corporation, Tokyo, Japan), a 2-mm hole in the right Th10 vertebral arch was drilled. Special care was taken not to injure the dura, and for thermal protection, trepan was cooled down with chilled phosphate-buffered saline (PBS). Subsequently, the impactor tip was placed within the hole, contacting the dura mater but exerting no pressure on it. A single air blast (150 kPa pressure; $0.1 \mathrm{sec}$ duration) was applied. The air blast shot was observed under the stereomicroscope and recorded by the attached camera (Invenio 5D; Nikon Corporation). After completing the procedure, the hole was secured with bone wax, muscles were sutured in layers, skin was closed and the wound was treated with a sterile bandage. This procedure was performed on all adult rats in the $\mathrm{C}$ and $\mathrm{M}$ groups.

To avoid dehydration, all rats were subcutaneously injected with $2 \mathrm{ml}$ sterile saline. As the autonomic function of the urinary bladder was impaired due to the spinal shock, rat bladders were emptied manually twice daily until the recurrence of bladder function. To prevent pain, $400 \mathrm{mg}$ paracetamol (suspension $125 \mathrm{mg} / 5 \mathrm{ml}$; POLFA Łódź) was dissolved in $100 \mathrm{ml}$ drinking water (average drug dosage, $200 \mathrm{mg} / \mathrm{kg}$ body weight daily).

Cell cultures. Primary mixed glial cultures were prepared from 45 2-day-old Wistar rat pups, as described previously (15). Briefly, following decapitation the brains were excised aseptically and separated from the blood vessels and meninges on ice. Cerebral cortical tissue was dissociated by trituration in ice-cold Dulbecco's modified Eagle medium (DMEM; $4.5 \mathrm{~g}$ 
glucose/l) supplemented with $10 \%$ heat-inactivated fetal bovine serum (FBS), $2 \mathrm{mM}$ glutamine, $100 \mathrm{UI} / \mathrm{ml}$ penicillin, $100 \mu \mathrm{g} / \mathrm{ml}$ streptomycin and $5 \mu \mathrm{g} / \mathrm{ml}$ fungizone (all Invitrogen; Thermo Fisher Scientific, Inc., Waltham, MA, USA). The suspension was filtered sequentially through two cell strainers with 70- and 40- $\mu \mathrm{m}$ meshes (BD Biosciences, Franklin Lakes, NJ, USA). Dissociated cells were plated $\left(20 \times 10^{6}\right.$ cells/dish $)$ on poly-D-lysine-coated 100-mm Petri dishes (BD Biosciences) and incubated at $37^{\circ} \mathrm{C}$ in humidified $5 \% \mathrm{CO}_{2} / 95 \%$ air $\left(\mathrm{CO}_{2}\right.$ incubator; Heraeus, Hanau, Germany). The medium was replenished 1 day after plating and changed every 3 days thereafter. Subsequent to plating, the cells were cultured for 13-15 days until confluence. Poly-D-lysine was purchased from Sigma-Aldrich (Merck KGaA, Darmstadt, Germany).

To identify astrocytes, the cultures were fixed in cold $99.8 \%$ methanol for $10 \mathrm{~min}$ at $4^{\circ} \mathrm{C}$ (Sigma-Aldrich; Merck $\mathrm{KGaA}$ ) and labeled immunocytochemically with glial fibrillary acidic protein (rabbit anti-GFAP; catalogue no. ab7260; 1:500 dilution, overnight at $4^{\circ} \mathrm{C}$ ), which is a specific marker for astrocytes, and secondary anti-rabbit antibody ( $\mathrm{IgG}$, catalogue no. ab7090, dilution $1: 10,000$ for $1 \mathrm{~h}$ at $20^{\circ} \mathrm{C}$; both $\mathrm{Abcam}$, Cambridge, MA, USA). Analysis with light microscope (magnification x400; Olympus BH2, Olympus Corporation, Tokyo, Japan) of these mixed glial cultures demonstrated that $70-75 \%$ of the cells were GFAP-positive. Of the cultured cells, $\sim 20 \%$ reacted with Ricinus communis agglutinin-1 (RCA-1; Vector Laboratories, Inc., Burlingame, CA, USA), a marker for microglia (examined under $488 \mathrm{~nm}$ fluorescence, microscope and magnification as above). No neurons were detected, as confirmed using light microscopy after immunostaining of cells, fixed as described, with a monoclonal antibody against microtubule associating protein-2 (rabbit anti-MAP-2; catalogue no. ab32454; 1:500 dilution, overnight at $4^{\circ} \mathrm{C}$ and $\mathrm{IgG}$ anti-rabbit secondary antibody at a dilution of 1:10,000 for $1 \mathrm{~h}$ at $20^{\circ} \mathrm{C}$ (Abcam).

Rat microglial cultures were obtained by shaking the primary mixed glial cultures at $200 \mathrm{r} / \mathrm{min}$ for $5 \mathrm{~h}\left(37^{\circ} \mathrm{C}\right)$, with maximum yields between days 12 and 14. The suspension of floating cells was filtered through a 40-mm nylon mesh, centrifuged at $200 \mathrm{x}$ g for $10 \mathrm{~min}$, suspended in $200 \mu \mathrm{l}$ DMEM supplemented with $10 \%$ FBS, plated in 96-well tissue culture plates $\left(5 \times 10^{4}\right.$ cells/well) and incubated at $37^{\circ} \mathrm{C}$ for $15 \mathrm{~min}$ in humidified $5 \% \mathrm{CO}_{2} / 95 \%$ air. Subsequently, the wells were vigorously washed three time with $200 \mu$ l culture medium to remove non-adherent cells. Microglial cells, which firmly adhered to the bottom of the well, were incubated at $37^{\circ} \mathrm{C}$ overnight. To stimulate the microglial cells, $1 \mu \mathrm{g} / \mathrm{ml}$ lipopolysaccharide (LPS; Sigma-Aldrich; Merck KGaA) was added for $24 \mathrm{~h}$ at $37^{\circ} \mathrm{C}$. The effectiveness of stimulation was determined by measuring the concentration of IL-1 $\beta$ (catalogue no. SRLB00), IL-6 (catalogue no. SR600B) and TNF- $\alpha$ (catalogue no. SRTA00) in the culture medium using rat ELISA kits (Quantikine ELISA Kits; R\&D Systems, Inc., Minneapolis, MN, USA), according to manufacturer's recommendations. Absorbance was measured using a microplate reader at a wavelength of $450 \mathrm{~nm}$. The limit of the assay was $4.4 \mathrm{pg} / \mathrm{ml}$ for IL-1 $\beta, 19 \mathrm{pg} / \mathrm{ml}$ for IL-6 and $15 \mathrm{pg} / \mathrm{ml}$ for TNF- $\alpha$. The intra-assay coefficients of variability for all cytokines were $<10 \%$. After $24 \mathrm{~h}$ of LPS stimulation, the medium was removed and the cells were dissociated by trituration in ice-cold PBS.
Microglial suspensions were filtered through $40-\mu \mathrm{m}$ meshes, adjusted to $1 \times 10^{6}$ cells $/ \mathrm{ml}$ and a constant number of microglia were thus prepared for implantation.

To differentiate transplanted cells, cells were labeled with freshly prepared $2 \mu \mathrm{M} / 1$ Cell Tracker CM-DiI solution (Molecular Probes; Thermo Fisher Scientific, Inc.) at $37^{\circ} \mathrm{C}$ for $5 \mathrm{~min}$, and at $4^{\circ} \mathrm{C}$ for $15 \mathrm{~min}$. Excess tracer was washed away with PBS and cells were suspended in fresh culture medium to obtain $\sim 300$ cells in $10 \mu$ l. Cell viability was determined by assessing membrane integrity in the microglial cultures using a $0.1 \%$ trypan blue exclusion test and MTT test with a final MTT concentration of $2.5 \mu \mathrm{g} / \mathrm{ml}$ in PBS. Dimethyl sulfoxide was used as the solvent (Invitrogen; Thermo Fisher Scientific, Inc.), measured at a wavelength of $570 \mathrm{~nm}$ (xMark Microplate Spectrophotometer; Bio-Rad Laboratories, Inc., Hercules, CA, USA), as previously described (16). More than 97-98\% of the cultured cells were living, 95\% reacted with RCA-1 (microglial cells), and only 2-3\% were GFAP-positive (astrocytes) (17). All intervals and compound concentrations used in the present study were within the limits used in in vitro experiments considering microglia and LPS $(15,18)$.

Cell transplantation. In group M, cultured LPS-activated and DiI-labeled microglial cells ( 300 cells/injection) were injected twice into the site of injury. The initial injection was administered immediately after SCI and the second injection was administered $24 \mathrm{~h}$ later. The dura mater was incised with the tip of an injection needle, exposing the surface of the injured spinal cord. For each injection, $10 \mu \mathrm{l}$ microglial cell suspension (group M) or saline (group C) was slowly injected, at an angle of $45^{\circ}$, into the dorsal spinal cord next to the middle line at the lesion site using a spinal stereotaxic frame (manufactured at Department of Physiology, School of Medicine in Katowice, Katowice, Poland) by means of a glass pipette connected to a Hamilton syringe with a tip outer diameter of $100 \mu \mathrm{m}$. In order to confirm that transplanted microglial cells were delivered successfully into the injured spinal cord, spinal cord sections collected from a small set of animals $(n=2)$ $24 \mathrm{~h}$ post-transplantation were examined using a fluorescent microscope (Labophot 2; Nikon Corporation) under a $568 \mathrm{~nm}$ wavelength to visualize exogenous DiI-labeled microglia cells present in the spinal cord.

Assessment of locomotor function. During 12 weeks after the surgical procedure, animals were observed and analyzed regarding development and/or regression of neurological deficits. Behavioral observations included gait analysis (foot print test) and open field tests, according to the Basso, Beattie and Bresnaham (BBB) scale (19).

Foot print tests were conducted once in postoperative weeks 1, 4, 7 and 12. Animals were tested on a 100-cm long and $7-\mathrm{cm}$ wide runway with side walls and a transparent bottom. The walk of a rat through the runway was recorded with a digital camera and was automatically analyzed frame by frame (Catwalk XT 8.1; Noldus Information Technology, Wageningen, The Netherlands). Each animal was tested three times, consecutively. Framed foot images were analyzed regarding the foot rotation angle (the angle made by two lines connecting the third toe and the stride line at the center of the paw) of the right hind paw (ipsilateral to the 
injury site), and interlimb coordination (smallest distance between the middle point of the hind paw and forepaw on the same side). Normal rotation angle is $\sim 8^{\circ}$ and after trauma this increases up to $30^{\circ}$ (20). Interlimb coordination is $\sim 1.5 \mathrm{~cm}$ in healthy rats and increases to $3 \mathrm{~cm}$, or more, following injury (20).

The BBB open field test was carried out in a classical way on a plexiglass surface (19). During the test, motor function of joints was analyzed to assess the stepping ability of the rats. Additionally, general coordination and stability of the body were evaluated. The value range was $0-22$, where 0 was related to complete lack of motor capability and 22 indicated the best score in this aspect. Obtained results were average values from both hind extremities.

Neuroanatomical tracing. Retrograde neuroanatomical tracing was used to determine the extent to which supraspinal neurons were able to regrow axons to reach spinal cord segments caudal to the injury. A total of 4 rats from each group were randomly selected. One week before the end of the experiment, rats were anesthetized intraperitoneally with ketamine $(100 \mathrm{mg} / \mathrm{kg})$ and xylazine $(10 \mathrm{mg} / \mathrm{kg})$, the spinal cord was exposed by laminectomy below the injury site and two microcrystals of FluoroGold (FG; Fluorochrome Inc., Englewood, NJ, USA) were placed bilaterally inside the spinal cord, $10-\mathrm{mm}$ caudally from the injury site. For quantification of the number of FG-positive neurons present in the brain stem (red nucleus) and primary motor cortex, whole brains were carefully dissected, embedded in TissueTek (Sakura Finetek Europe B.V, Flemingweg, The Netherlands), frozen at $-80^{\circ} \mathrm{C}$ and then cut coronally into $10-\mu \mathrm{m}$ sections. Every sixth slide was analyzed, giving 18-22 sections per rat. The sections were viewed under a fluorescent microscope (Labophot 2; Nikon Corporation) at $365 \mathrm{~nm}$ and imaged at magnification of $x$ 400. FG-positive cells were counted in five constant sites (center and four corners of the image). Finally, the number of FG-positive cells in the brain stem and motor cortex per $\mathrm{mm}^{2}$ was calculated.

MRI analysis. MR images were obtained at the Institute of Nuclear Physics, Polish Academy of Sciences (Kraków, Poland) using a $4.7 \mathrm{~T}$ research MRI scanner, equipped with MARAN DRX digital console (Resonance Instruments, Ltd., Witney, UK). A measuring probe-head with surface radiofrequency coil dedicated for rat spinal cord investigations was used. Animals were anesthetized with halothane $(2 \%)$ mixed with air $(60 \% / 1.2 \mathrm{l} / \mathrm{min})$ and oxygen $(40 \% / 0.8 \mathrm{l} / \mathrm{min})$. Physiological conditions of the animal, including temperature, breathing rate and cardiac rate, were continuously monitored during examination using an MR-compatible Small Animal Monitoring \& Gating System (SA Instruments, Inc., Stony Brook, NY, USA).

A spin echo pulse sequence was used for acquiring $\mathrm{T}_{2}$-weighted and diffusion-weighted MR images in sagittal and axial projections. The following parameters of the spin echo sequence were applied: Echo time, $32 \mathrm{msec}$; repetition time, $1.8 \mathrm{sec}$; field of view, $2.5 \mathrm{~cm}$; image matrix size, 128x 128; and slice thickness, $1.5 \mathrm{~mm}$. The signal was accumulated [number of acquisitions (NA)=6] in order to improve the signal-to-noise ratio (SNR).
Diffusion-weighted images were obtained with additional diffusion sensitive gradients $(\delta=5 \mathrm{msec}$ and $\Delta=23 \mathrm{msec})$ added to the spin echo sequence in transversal and longitudinal directions to the spinal cord axis $(21,22)$. In order to optimize the SNR, thus minimizing the examination time, different values of $b$-factor were used to assess the effect of water diffusion on the echo signal: 750 and $1,100 \mathrm{sec} / \mathrm{mm}^{2}$ for longitudinal and transversal directions, respectively $(14,23)$. The acquisition was both cardiac- and respiratory-gated in order to eliminate motion artifacts.

Histomorphological analysis. After 1 ( $\mathrm{n}=5$ for each group) and 12 weeks ( $n=6$ for each group), respectively, rats were re-anesthetized and perfused transcardially with $100 \mathrm{ml}$ PBS (pH 7.4) followed by $100 \mathrm{ml} 4 \%$ paraformaldehyde solution in the same buffer. Fragments of spinal cord $(\sim 2 \mathrm{~cm})$ incorporating the injured area were dissected and dehydrated in $20 \%$ sucrose in PBS for $24 \mathrm{~h}$ at $4^{\circ} \mathrm{C}$. Spinal cords were then embedded in TissueTek, frozen at $-80^{\circ} \mathrm{C}$, cut sagittally or transversally into $10-\mu \mathrm{m}$ sections and mounted on SuperFrost Plus slides (Menzel-Glaser; Thermo Fisher Scientific, Inc.) in a 10 -section step manner. Slides were subjected to routine hematoxylin and eosin (H\&E) staining at room temperature: $\mathrm{H} \& \mathrm{E}$ staining for $5 \mathrm{~min}$, followed by a $15 \mathrm{~min}$ tap-water wash, and 2 min eosin staining; $1 \%$ toluidine staining at room temperature for $15 \mathrm{~min}$; or immunohistochemical labeling. The following anti-rat antibodies were used (all Chemicon ${ }^{\circledR}$; EMD Millipore, Billerica, MA, USA): Rabbit anti-OX-42 (for microglia and macrophages; catalogue no. CBL1512; dilution 1:100), mouse ED-1 (catalogue no. MAB1435; dilution 1:100) and rabbit GFAP (for astrocytes; catalogue no. AB5804; dilution 1:500). The sections were incubated with primary antibodies overnight at $4^{\circ} \mathrm{C}$, and after washing three times with PBS, the sections were treated for $2 \mathrm{~h}$ at room temperature in a dark chamber with secondary goat anti-rabbit immunoglobulin (Ig G or anti-mouse IgG antibodies conjugated with AlexaFluor 488 and/or AlexaFluor 568 (Molecular Probes; Thermo Fisher Scientific, Inc.; goat Anti-Mouse IgG AlexaFluor 488, catalogue no. A11001; goat Anti-Mouse IgG AlexaFluor 568, catalogue no. A11004; A11008 for goat Anti-Rabbit IgG AlexaFluor 488, catalogue no. A11008; goat Anti-Rabbit IgG AlexaFluor 568, catalogue no. A11011; dilution 1:500). Coverslips were placed over the sections with VectaShield and DAPI (Vector Laboratories, Inc., ) and sections were examined under a confocal laser scanning microscope (FluoView; Olympus Corp., Tokyo, Japan) at a magnification of $x 400$. The images were digitally stored and then analyzed. Maximal distance of expansion of implanted microglia in the injured spinal cord was measured 1 week after surgery and survival of transplants (number of cells seen in the epicenter of the injury) was examined 1 and 12 weeks following surgery, respectively. Sizes of lesions (cavity area) were also measured 12 weeks after surgery.

Statistical analysis. Analysis of variance (ANOVA), two-way repeated measures and/or one-way ANOVA with Tukey's post hoc tests [honest significant difference (HSD) or unequal $\mathrm{N} \mathrm{HSD,} \mathrm{where} \mathrm{N}$ is the number of samples used] or nonparametric Kruskal-Wallis ANOVA were used to analyze normally distributed data or non-continuous data, respectively. 

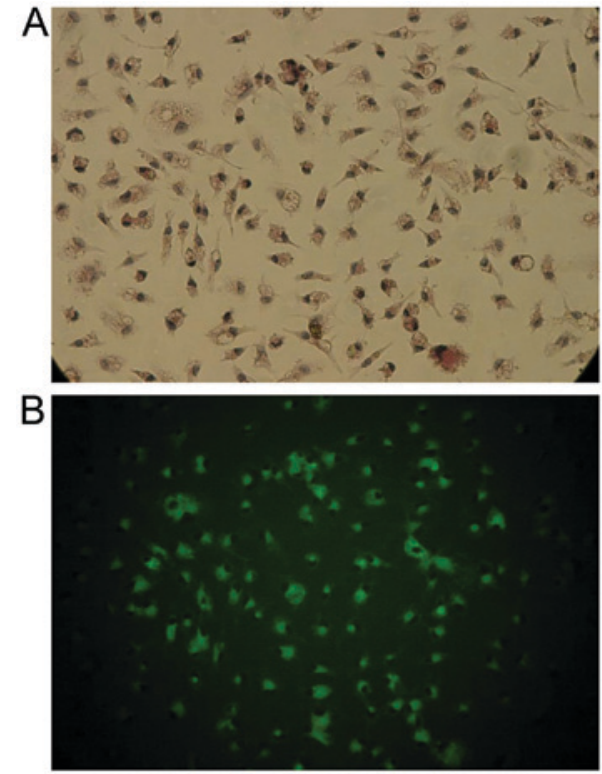

Figure 1. Isolated microglial cells. Isolated microglial cells viewed under a (A) light and (B) epifluorescent microscope labelled with Ricinus communis agglutinin-1. Magnification, $\mathrm{x} 100$.
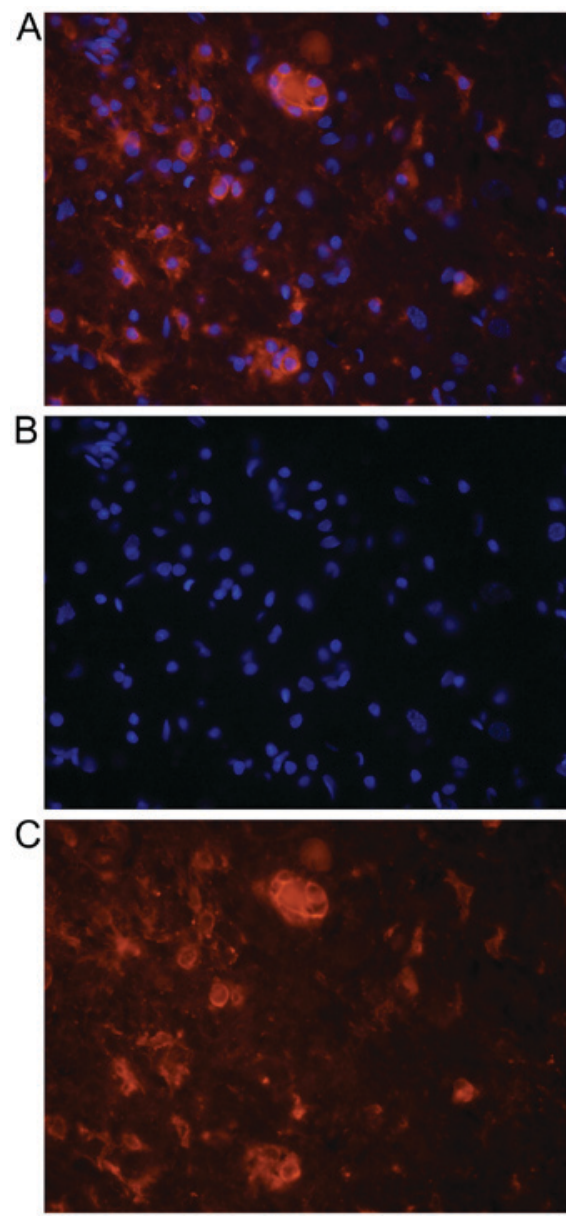

Figure 2. Representative photographs demonstrating DiI-labeled microglial cells one day after transplantation. (A) Double labeling (DiI and DAPI), (B) DAPI-labeled nuclei and (C) DiI-labeled cytoplasm of microglia. Cells demonstrated a typically round morphology in the nearest vicinity of the main lesion. Microsphere or tumor like formation of these cells is observed. Magnification, x200. DiI, 1,1'-Dioctadecyl-3,3,3',3'-Tetramethylindocarbocyanine Perchlorate; DAPI, 4,6-diamidino-2-phenylindole.

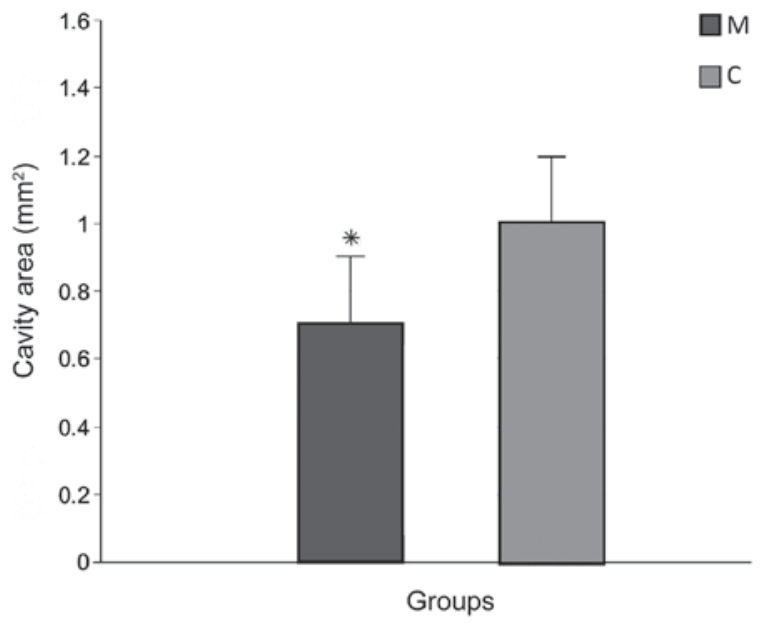

Figure 3. Lesion cavity area observed 12 weeks after spinal cord injury in the $\mathrm{M}$ and $\mathrm{C}$ groups. Data are presented as the mean \pm standard deviation. ${ }^{*} \mathrm{P}<0.05$ vs. group C. $\mathrm{M}$, experimental group; $\mathrm{C}$, control group.

Differences in foot print, histological and BBB scores between group means at each time point post injury were identified using Student's t-tests. STATISTICA, version 10 software (StatSoft; Dell, Round Rock. TX, USA) was used. P<0.05 was considered to indicate a statistically significant difference. All data were expressed as the mean \pm standard deviation.

\section{Results}

Histopathological findings. Transplanted activated microglial cells, as confirmed by double labeling with DiI and OX-2 (Fig. 1), were observed 1 week after transplantation inside the spinal cord in the closest vicinity of injury and injection site (expansion, $2.7 \pm 1.3 \mathrm{~mm}$ ). They formed microsphere-like structures (Fig. 2). Their number rapidly decreased with time; 1 week after surgery $371.1 \pm 63.7$ cells $/ \mathrm{mm}^{2}$ were observed, while at the end of the experiment, no cultured microglia were present inside the spinal cord.

The average length of the lesions measured on H\&E-stained sections in group $\mathrm{M}(2.9 \pm 0.13 \mathrm{~mm})$ was significantly smaller than group $\mathrm{C}(6.32 \pm 2.41 \mathrm{~mm} ; \mathrm{P}<0.05$; data not shown). The cavity area of the main lesion was also significantly decreased in group $\mathrm{M}\left(0.7 \pm 0.08 \mathrm{~mm}^{2}\right)$ compared with group $\mathrm{C}$ $\left(1.02 \pm 0.21 \mathrm{~mm}^{2} ; \mathrm{P}<0.05\right.$; Figs. 3 and $\left.4 \mathrm{~A}\right)$.

Neuroanatomical tracing. FG-positive cells in the brain stem (Fig. 4B) and primary motor cortex, demonstrating survival of long-track motor neurons, were more numerous in group $\mathrm{M}$ $(203.7 \pm 123.3)$ than in group C (14.3 \pm 3.3$)$, and this difference was significant $(\mathrm{P}<0.05$; Fig. 5). Tracer spread through the blood was absent in all rats, as confirmed by microscope observation during the application procedure.

MRI analysis. Fig. 6 demonstrates MRI images and reconstructed parametric maps from representative spinal cords in group R. Fig. 7 demonstrated corresponding images from a representative injured spinal cord treated with microglia from group $M$. The average values of longitudinal and transverse diffusion coefficients (DL and DT, respectively) for the M, C and R groups are demonstrated in Figs. 8 and 9. 


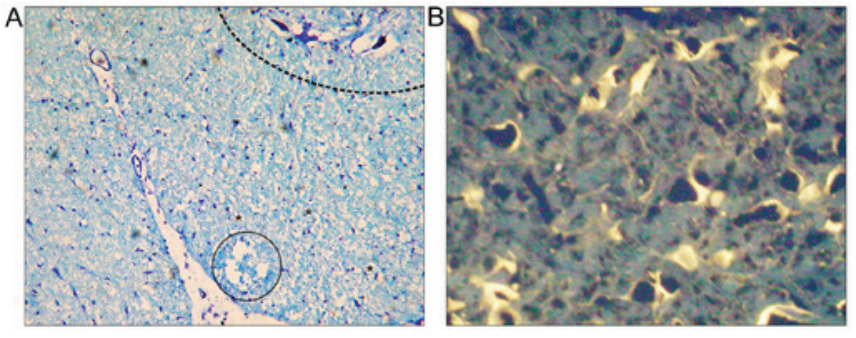

Figure 4. Microphotographs obtained 12 weeks after spinal cord injury in rats treated with microglia cells. (A) Microphotograph of spinal cord with toluidine blue staining. Dashed-line area indicates anterior horn of spinal cord. Numerous cystic cavitations were observed (vacuolar structures marked by asterisks) and one larger cavity was visible in the injured spinal cord ventral white column (in the circle). Magnification, x100; (B) FG retrograde labeling of regenerating neurons. Neuronal cytoplasm was labeled by FG in transverse sections of the brain stem. FG, FluoroGold. Magnification, x400.

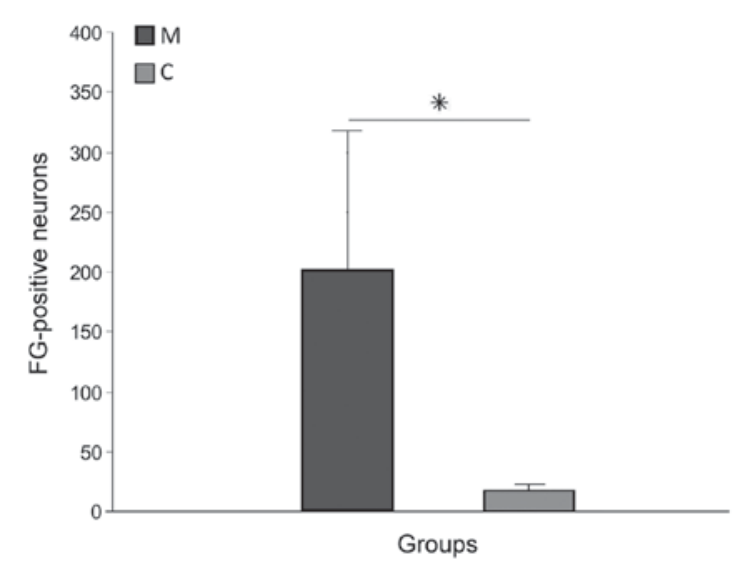

Figure 5. Total number of FG-positive brain stem and motor cortex neurons found 12 weeks after spinal cord injury in the $\mathrm{M}$ and $\mathrm{C}$ groups. Data are presented as the mean \pm standard deviation. ${ }^{*} \mathrm{P}<0.05$ as indicated. FG, FluoroGold; M, experimental group; C, control group.

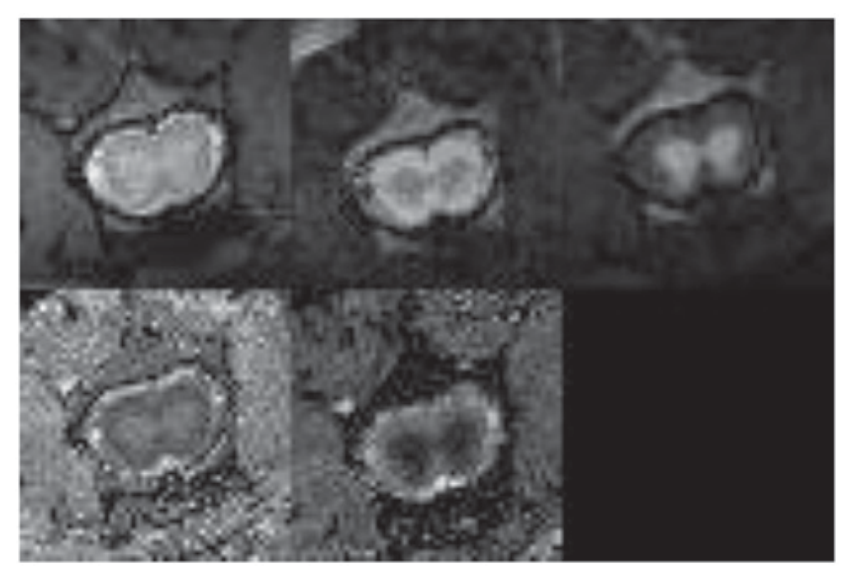

Figure 6. Magnetic resonance images and reconstructed parametric maps from representative spinal cord in reference (healthy) group. In the top row from left to right: $\mathrm{T}_{2}$-weighted image; diffusion-weighted image with diffusion gradient applied along transverse direction; and diffusion-weighted image with diffusion gradient applied along longitudinal direction. In the bottom row from left to right: Transverse diffusivity map and longitudinal diffusivity map.

The average DL value in group C (Fig. 8) was significantly lower than in the R group (Tukey's unequal N HSD test;

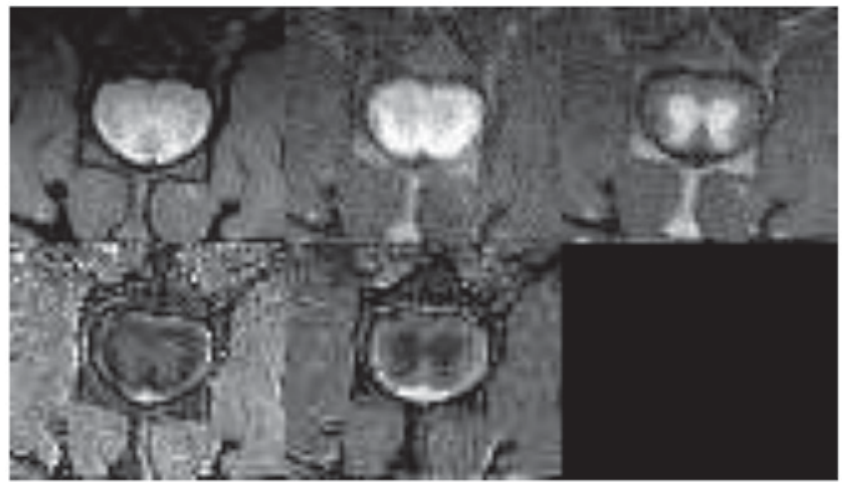

Figure 7. Magnetic resonance images and reconstructed parametric maps from representative spinal cord in group of injured spinal cords treated with microglia. In the top row from left to right: $\mathrm{T}_{2}$-weighted image; diffusion-weighted image with diffusion gradient applied along transverse direction; and diffusion-weighted image with diffusion gradient applied along longitudinal direction. In the bottom row from left to right: Transverse diffusivity map and longitudinal diffusivity map. A lack of cysts or other macroscopic changes in the white matter was observed.

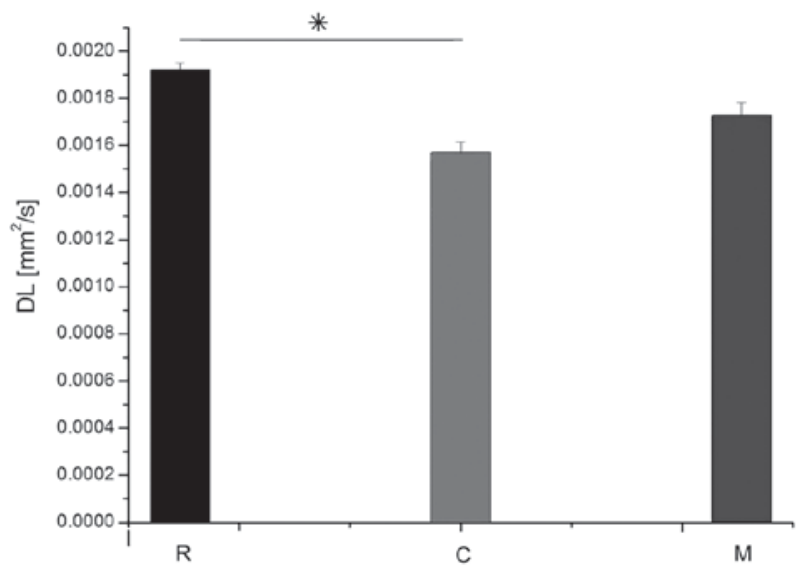

Figure 8. Average values of DL in groups R, C and M. Data are presented as the mean \pm standard deviation. ${ }^{*} \mathrm{P}=0.0012$ as indicated. DL, longitudinal diffusion coefficient; $\mathrm{R}$, reference group; $\mathrm{C}$, control group; $\mathrm{M}$, experimental group.

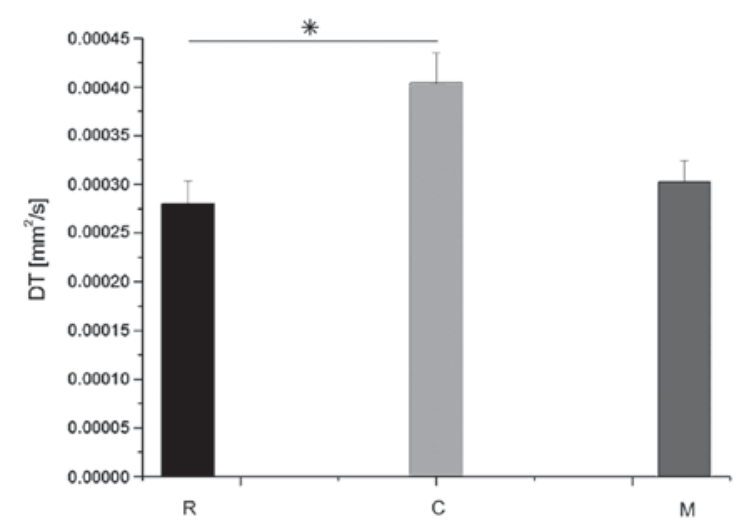

Figure 9. Average values of DT in groups R, C and M. Data are presented as the mean \pm standard deviation. ${ }^{*} \mathrm{P}=0.027$ as indicated. DT, transverse diffusion coefficient; $\mathrm{R}$, reference group; $\mathrm{C}$, control group; $\mathrm{M}$, experimental group.

$\mathrm{P}=0.0012$ ). No significant differences were observed between the average DL value in the $\mathrm{M}$ and $\mathrm{C}$ groups or 


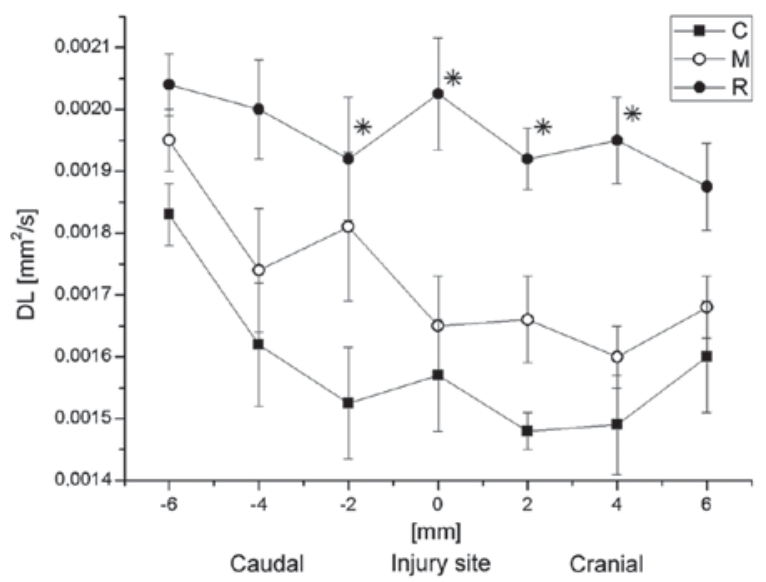

Figure 10. Average values of DL in groups R, C and M at the site of injury and in the vicinity. Data are presented as the mean \pm standard deviation. ${ }^{*} \mathrm{P}<0.05$ vs. group C. DL, longitudinal diffusion coefficient; R, reference group; $\mathrm{C}$, control group; $\mathrm{M}$, experimental group.

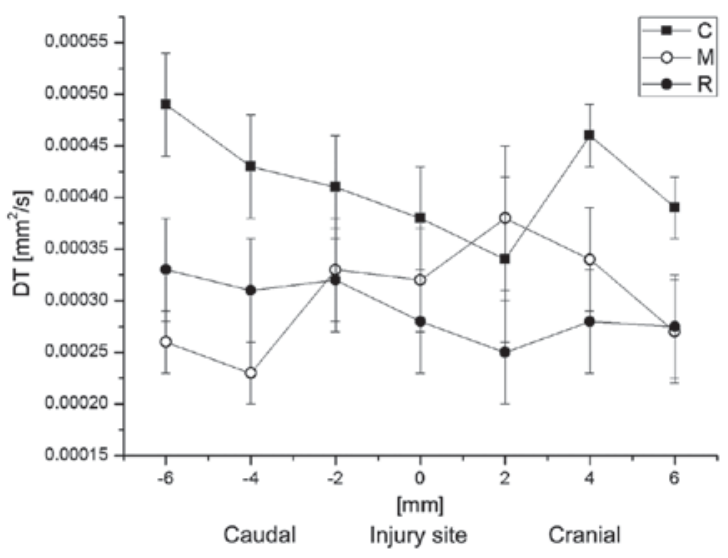

Figure 11. Average values of DT in groups R, C and M at the site of injury and in the vicinity. Data are presented as the mean \pm standard deviation. DT, transverse diffusion coefficient; R, reference group; C, control group; $\mathrm{M}$, experimental group.

between the average DL value in the $\mathrm{M}$ and $\mathrm{R}$ groups. The average DT value (Fig. 9) in group C was significantly higher (Tukey's unequal N HSD; $\mathrm{P}=0.027$ ) than in group $\mathrm{R}$, while the remaining comparisons demonstrated no significant differences, similarly as for the DL coefficient. For both parameters, average values demonstrated in group $M$ were closer to the group $\mathrm{R}$ values.

Subsequently, the correlation between DT or DL with the distance from the injury site was analyzed. The average values of DL and DT at the particular spinal cord levels are demonstrated in Figs. 10 and 11, respectively. DL values in group $\mathrm{C}$ were significantly lower than in the group R 2-mm caudally to the injury site, at the injury site, and at 2 and $4-\mathrm{mm}$ cranially to the injury site (Fisher's least significant difference test; $\mathrm{P}=0033,0.039,0.023$ and 0.027 , respectively), while no significant difference was observed between them at the caudal side from the injury. In general, the DL values in group $\mathrm{M}$ were closer to the group $\mathrm{R}$ values (Fig. 10). At the caudal side, results for group $\mathrm{C}$ were also nearer those of group R. DT values for all groups did not demonstrate any significant differences between each other at any spinal cord level. However, the DL and DT values for group M were generally closer to the respective values for group $\mathrm{R}$ (Fig. 11).

Behavioral study. Immediately after SCI, the majority of rats were monoplegic; 14 rats in $\mathrm{M}$ group and all in $\mathrm{C}$ group. The hind paw angle of rotation increased in all rats in the first week after surgery, and reached $20.3 \pm 1.1^{\circ}$ in group $C$ rats at the end of experiment, indicating marked deterioration of locomotor function following injury. In group $M$, at week 12 after surgery, this parameter had decreased; however, this decrease was not significant compared with group $\mathrm{C}\left(18.9 \pm 0.8^{\circ}\right)$. The differences appeared in week 7 of observation, where the angle of rotation in group $\mathrm{M}$ was significantly lower than that in group $\mathrm{C}(\mathrm{P}<0.05$; Fig. 12). Interlimb coordination improved significantly in animals treated with microglia compared with those in group $\mathrm{C}$ at weeks 4,7 and 12 of observation $(\mathrm{P}<0.05)$, reaching a value of $1.61 \pm 0.36 \mathrm{~cm}$ at week 12 , compared with $2.17 \pm 0.41 \mathrm{~cm}$ in group C (Fig. 13).

BBB tests revealed improved dynamics of recovery of function in group $\mathrm{M}$ compared with group $\mathrm{C}$. The index value, which was $<101$ week after SCI in all rats, did not improve after 12 weeks in rats in group C $(10.1 \pm 0.3)$, while in group $M$ the index increased significantly by weeks 7 and 12, reaching $17.5 \pm 0.3$ at week 12 ( $\mathrm{P}<0.05$; Fig. 14).

\section{Discussion}

On the basis of the present results, a potentially beneficial role of activated microglia in the treatment of SCI cannot be excluded. Both morphological features of injury and functional status were improved in rats that received implantations of microglial cells in the vicinity of injury. The predominant idea of delivery of microglia into the injured spinal cord was to scavenge the remnants of damaged neurons, which should improve regeneration by suppressing the inflammatory reaction (2). In the classical experiment, Schwartz et al (1) used cultured and activated autologous blood-derived macrophages to stimulate regeneration of injured spinal cord. Such a procedure has also been attempted in human therapy $(20,24)$. The present study focused on another population of phagocytic cells, microglia, which naturally occur in the brain and spinal cord.

The present study utilized glial cells from immature rats. From the studies of newborn infant rats, it has been demonstrated that there is no development of post-traumatic scarring at all, and cell response of microglia greatly differs from adults. It was observed that, in newborn rats, infiltration of microglial cells at the site of SCI was reduced and they disappeared quickly (after just a few days), covering only the nearest region of post-traumatic changes (25). Only single reports exist that demonstrate that intraspinal transplanted microglial cells were capable of stimulating regeneration of sensory neurons (26). Furthermore, in cell culture conditions, convincing evidence was obtained that a mixed population of microglia and Schwann cells stimulated the regeneration of sensory cells more effectively than either of these populations used separately (27). Thus, these studies indicated that microglia are able to improve the regeneration of selected populations of neurons and interact with other cell types in the spinal cord. A study by Yu et al for the first time demonstrated that delayed transplantation (7 days after SCI) of activated 


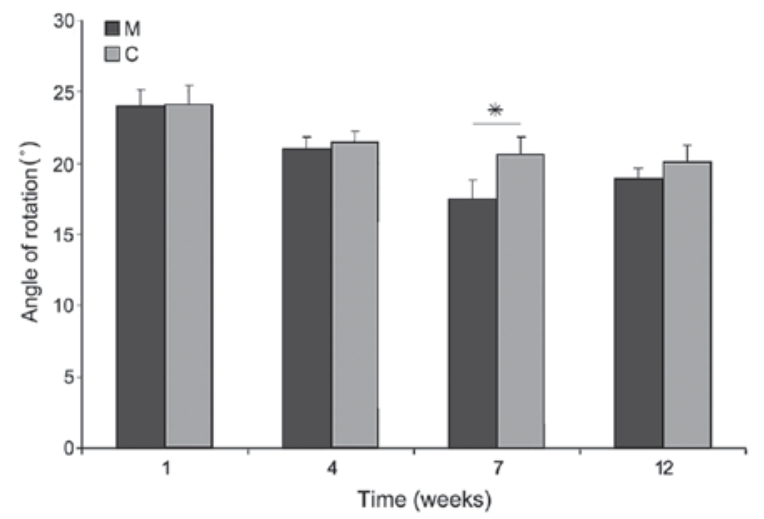

Figure 12. Angle of rotation of the hind paw after spinal cord injury in the $\mathrm{M}$ and $\mathrm{C}$ groups. Data are presented as the mean \pm standard deviation. ${ }^{*} \mathrm{P}<0.05$ as indicated. $\mathrm{C}$, control group; $\mathrm{M}$, experimental group.

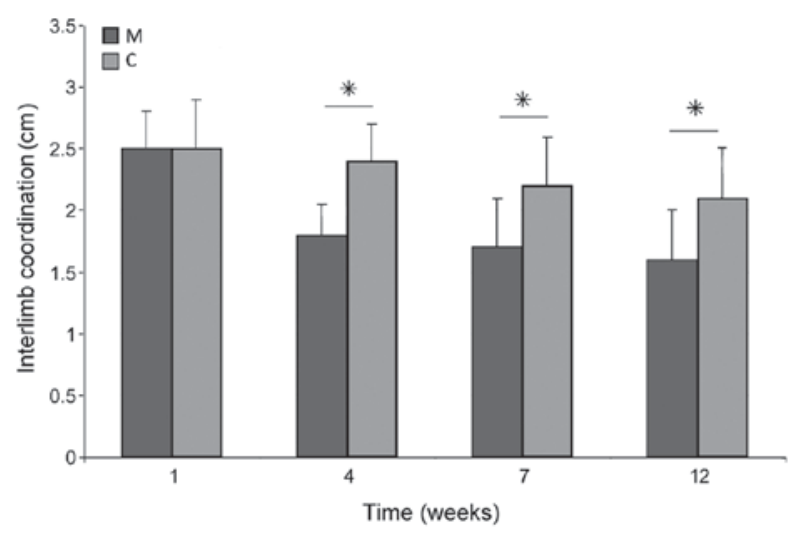

Figure 13. Interlimb coordination after spinal cord injury in the $\mathrm{M}$ and $\mathrm{C}$ groups. Data are presented as the mean \pm standard deviation. ${ }^{*} \mathrm{P}<0.05$ as indicated. $\mathrm{C}$, control group; $\mathrm{M}$, experimental group.

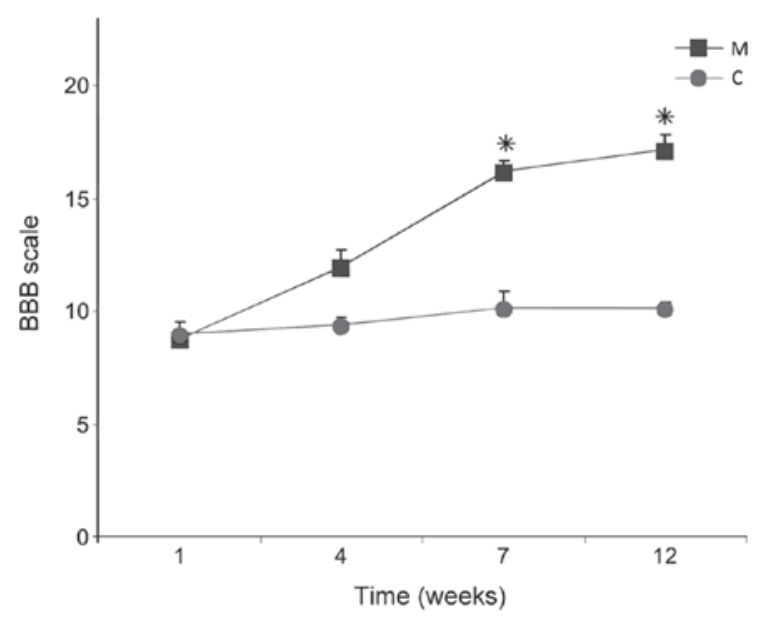

Figure 14. BBB open field scores 12 weeks after spinal cord injury in the $\mathrm{M}$ and $\mathrm{C}$ groups. Data are presented as the mean \pm standard deviation ${ }^{*} \mathrm{P}<0.05$ vs. group C. BBB, Basso, Beattie and Bresnaham; C, control group; $\mathrm{M}$, experimental group.

microglial cell suspension directly into the injured spinal cord area improved the hind limb motor function recovery and reduced the size of the liquefaction necrosis area. The extent of lower limb motor function improvement has a positive correlation with the number of aggregated microglia. Furthermore, this demonstrated that the functions of microglial cells may be modified pharmacologically, by neutralizing IL-6 action by blocking the availability of its specific receptor (28). As a result, in the injured spinal cord, level and activity of granulocyte macrophage colony-stimulating factor, a potent mitogen factor for microglial cells, increased and in turn led to a rapid decrease in the amount of degradation products of myelin and Nogo-A protein, a well-known inhibitor of axonal outgrowth (29). Consequently, this resulted in increased re-growth and sprouting of axons, and the final result was the improvement of motor function (29).

There are also works that have indicated that suppression of the inflammatory reactions of microglia in the injured spinal cord through the application of hypothermia may have positive influences on the structure of the spinal cord, as well as on the recovery of lost motor function (30). It has been also been demonstrated that $\mathrm{T}$ - and $\mathrm{B}$-lymphocytes restrict functional recovery from SCI by the increasing numbers of microglia/macrophages, as well as decreasing axonal sprouting and myelination (31). A study by Emmetsberger and Tsirka (32) suggested that suppressing microglia/macrophage activation with specific tripeptide macrophage/microglia inhibitory factor reduced secondary injury around the lesion epicenter in a dorsal hemisection model of SCI. It decreased the hypertrophic change of astrocytes and induced an increase in the number of axons present within the lesion epicenter (32). Furthermore, timely inhibition of microglial/macrophage activation prevented demyelination and axonal dieback by modulating oligodendrocyte survival and oligodendrocyte precursor maturation (32).

To speed up the treatment of SCI, the present study applied microglia already pre-activated in culture. However, one must consider the side effects of the use of microglia in an active form, which is the possibility of their 'hyperstimulation', leading to the origin of so-called hyperreactive cells. Such cells secrete many substances toxic to neurons, such as TNF- $\alpha$, prostaglandin E2 or nitric oxide, in contrast to non-stimulated microglial cells that produce rather neurotrophic factors (33). Fortunately, such a situation requires specific conditions. In the microglial cell culture used in the present study, a relatively low concentration of LPS was chosen, empirically based on previous tests (unpublished data), to avoid hyperstimulation of microglia. The results of the present study indicated a potential positive influence of activated microglia on the regeneration of spinal cord white matter.

In conclusion, the present study demonstrated that delivery of activated microglia to the injured spinal cord may be an effective method for the repair of white matter. Activated microglia may be one of the optimal candidates for the repair of spinal cord after injury. Nevertheless, this issue requires further investigation, particularly if its future implementation into human therapy is concerned.

\section{Acknowledgements}

The present study was supported by the Medical University of Silesia (grant nos. KNW-1-030/P/1/0 and KNW-1-026/P/2/0). The results of the current study were presented on July 15,2012, at 8th FENS Forum in Barcelona 14-18.07.2012 (presentation 
code 12.26, Abstract Number 3472, Poster Board Number C111).

\section{References}

1. Schwartz M, Cohen I, Lazarov-Spiegler O, Moalem G and Yoles E: The remedy may lie in ourselves: Prospects for immune cell therapy in central nervous system protection and repair. J Mol Med (Berl) 77: 713-717, 1999.

2. Schwartz M: Macrophages and microglia in central nervous system injury: Are they helpful or harmful? J Cereb Blood Flow Metab 23: 385-394, 2003.

3. Moalem G, Leibowitz-Amit R, Yoles E, Mor F, Cohen IR and Schwartz M: Autoimmune T cells protect neurons from secondary degeneration after central nervous system axotomy. Nat Med 5: 49-55, 1999.

4. Loane DJ and Byrnes KR: Role of microglia in neurotrauma. Neurotherapeutics 7: 366-377, 2010.

5. Del Río Hortega P: La neuroglía normal. Conceptos de neurogliona y angiogliona. Arch Histol Norm Patol 1: 5-71, 1942.

6. Walker PA, Shah SK, Jimenez F, Aroom KR, Harting MT and Cox CS Jr: Bone marrow-derived stromal cell therapy for traumatic brain injury is neuroprotective via stimulation of non-neurologic organ systems. Surgery 152: 790-793, 2012.

7. Miyake T, Tsuchihashi Y, Kitamura and Fujita S: Immunohistochemical studies of blood monocytes infiltrating into the neonatal rat brain. Acta Neuropathol 62: 291-297, 1984.

8. Perry VH, Hume DA and Gordon S: Immunohistochemical localization of macrophages and microglia in the adult and developing mouse brain. Neuroscience 15: 313-326, 1985.

9. David S and Kroner A: Repertoire of microglial and macrophage responses after spinal cord injury. Nat Rev Neurosci 12: 388-399, 2011.

10. Fujita $S$ and Kitamura T: Origin of brain macrophages and the nature of the so-called microglia. Acta Neuropathol Suppl (Suppl 6): S291-S296, 1975

11. Li Y, Li D and Raisman G: Transplanted schwann cells, not olfactory ensheathing cells, myelinate optic nerve fibres. Glia 55: 312-316, 2007

12. Aloisi F: Immune function of microglia. Glia 36: 165-179, 2001.

13. Yaguchi M, Ohta S, Toyama Y, Kawakami Y and Toda M: Functional recovery after spinal cord injury in mice through activation of microglia and dendritic cells after IL-12 administration. J Neurosci Res 86: 1972-1980, 2008.

14. Marcol W, Slusarczyk W, Gzik M,Larysz-Brysz M, Bobrowski M, Grynkiewicz-Bylina B, Rosicka P, Kalita K, Węglarz W, Barski JJ, et al: Air gun impactor-a novel model of graded white matter spinal cord injury in rodents. J Reconstr Microsurg 28: $561-568,2012$

15. Labuzek K, Kowalski J, Gabryel B and Herman ZS Chlorpromazine and loxapine reduce interleukin-lbeta and interleukin-2 release by rat mixed glial and microglial cell cultures. Eur Neuropsychopharmacol 15: 23-30, 2005.

16. Mosmann T: Rapid colorimetric assay for cellular growth and survival: Application to proliferation and cytotoxicity assays. J Immunol Methods 65: 55-63, 1983.

17. Satoh J, Lee YB and Kim SU: T-cell costimulatory molecules B7-1 (CD80) and B7-2 (CD86) are expressed in human microglia but not in astrocytes in culture. Brain Res 704: 92-96, 1995.
18. Giri S, Nath N, Smith B, Viollet B, Singh AK and Singh I: 5-aminoimidazole-4-carboxamide-1-beta-4-ribofuranoside inhibits proinflammatory response in glial cells: A possible role of AMP-activated protein kinase. J Neurosci 24: 479-487, 2004.

19. Basso DM, Beattie MS and Bresnahan JC: A sensitive and reliable locomotor rating scale for open field testing in rats. J Neurotrauma 12: 1-21, 1995.

20. Karimi-Abdolrezaee S, Eftekharpour E, Wang J, Morshead CM and Fehlings MG: Delayed transplantation of adult neural precursor cells promotes remyelination and functional neurological recovery after spinal cord injury. J Neurosci 26: 3377-3389, 2006.

21. Weglarz WP, Jasiński A, Krzyżak AT, Kozłowski P, Adamek D, Sagnowski P and Pindel J: MR microscopy of water diffusion tensor in biological systems. Appl Magn Reson 15: 333-341, 1998.

22. Weglarz WP, Adamek D, Markiewicz J, Skórka T, Kulinowski P and Jasiński A: Analysis of the diffusion weighted MR microscopy data of excised spinal cord of a rat on the basis of model of restricted diffusion. Solid State Nucl Magn Reson 25: 88-93, 2004.

23. Minati L and Węglarz WP: Physical, foundations, models, and methods of diffusion magnetic resonance imaging of the brain: A review. Concepts Magnetic Resonance 30A: 278-307, 2007.

24. Knoller N, Auerbach G, Fulga V, Zelig G, Attias J, Bakimer R, Marder JB, Yoles E, Belkin M, Schwartz M and Hadani M: Clinical experience using incubated autologous macrophages as a treatment for complete spinal cord injury: Phase I study results. J Neurosurg Spine 3: 173-181, 2005.

25. Fujimoto Y, Yamasaki T, Tanaka N, Mochizuki Y, Kajihara H, Ikuta Y and Ochi M: Differential activation of astrocytes and microglia after spinal cord injury in the fetal rat. Eur Spine J 15: 223-233, 2006.

26. Prewitt CM, Niesman IR, Kane CJ and Houlé JD: Activated macrophage/microglial cells can promote the regeneration of sensory axons into the injured spinal cord. Exp Neurol 148: 433-443, 1997.

27. Hynds DL, Rangappa N, Ter Beest J, Snow DM and Rabchevsky AG: Microglia enhance dorsal root ganglion outgrowth in Schwann cell cultures. Glia 46: 218-223, 2004.

28. Yu TB, Cheng YS, Zhao P, Kou DW, Sun K, Chen BH and Wang AM: Immune therapy with cultured microglia grafting into the injured spinal cord promoting the recovery of rat's hind limb motor function. Chin J Traumatol 12: 291-295, 2009.

29. Mukaino M, Nakamura M, Yamada O, Okada S, Morikawa S, Renault-Mihara F, Iwanami A, Ikegami T, Ohsugi Y, Tsuji O, et al: Anti-IL-6-receptor antibody promotes repair of spinal cord injury by inducing microglia-dominant inflammation. Exp Neurol 224: 403-414, 2010.

30. Morino T, Ogata T, Takeba J and Yamamoto H: Microglia inhibition is a target of mild hypothermic treatment after the spinal cord injury. Spinal Cord 46: 425-431, 2008.

31. Wu B, Matic D, Djogo N, Szpotowicz E, Schachner M and Jakovcevski I: Improved regeneration after spinal cord injury in mice lacking functional T- and B-lymphocytes. Exp Neurol 237: 274-285, 2012

32. Emmetsberger $\mathbf{J}$ and Tsirka SE: Microglial inhibitory factor (MIF/TKP) mitigates secondary damage following spinal cord injury. Neurobiol Dis 47: 295-309, 2012.

33. Klusman I and Schwab ME: Effects of pro-inflammatory cytokines in experimental spinal cord injury. Brain Res 762: 173-184, 1997. 